\title{
SCHEMAT POLEMIKI Z MARCJONEM U IRENEUSZA Z LYONU I EZNIKA Z KOLB
}

Polemika z Marojonem zaprzątała umyszy wielu 0joón Kościoka. Ten zyjacy wI w. gnostyk, ktory swoje poglądy zawarł waginlonym dz1ele pt. "Antitheses" okazal sie szozególnie niebezpleczny zarómno dla wspólnoty Kościoła II w.. Jak 1 wieków późnjejszych. St.ąd tez - Jak wiadomo - mnozyły gie dzieła polemiozne przeciwko Marojonow1 1 marcjonitom od czasón mu mspózczesnyoh do kilkuset lat pózniejszych. Wóród najstarszych nalezy wspomnieó zaginiono dziełko Justyna ${ }^{1}$, zaginione dzlełko Teoflla $z$ Antiochi ${ }^{2}$ oraz Ireneusza "Adveraus haereses" ${ }^{3}$. W literaturze zacińsklef do najstarszych zaI1cza 818 "Adversus Marcionem" Tertuliana". Polemike podejmuja takte póniejsi Ojcow1e Kośoloła, zwaszcza greccy. Przenika ona takze do patrystycznej literatury armeśskiej. Jeden z ozokowych jej przedstawiolel1, Eznik z Kolb /V พ./ ostatnia IV ks18ge swego nap1sanego ok. 445-448 r. dzieka "De Deo"/arm. Eło Ałandoo/5 pośwtęca

1 Por. Eusebius, H.E. IV, 11,8, SCh 31,175, POK $3,158=$ Irenaeus, Adversus haereses IV, 6,2, SCh 100,440 .

2 Por. Eusebius, H.E. IV, 24, SCh 31,206-207, РОK 3,184.

3 PG T,437-1224/libr1 I-V/; ostatnie krytyczne mydanie: A.Rousseau - L.Doutreleau, Liber $I=$ SCh 263-264; liber II = SCh 293-294;

liber III = SCh 210-211; liber IV $x$ SCh 100; Iiber V = SCh 152-153.

4 PL 2,239-254, CC 1,437-726.

5 Wydane z tłumaozentem Irano.przez L.Mariès - Ch.Mercier, P0 28, Par1s 1959, fasc. 3-4, 413-776, [3-432]; Por. L.Mariès, Le "De Deo Uno" d'Eznlk de Kolb, connu sous le nom de "Contre les seotes". Etudes de oritique litteralre et textuelle, Paris 1924; Przekład nlem1eck1, S. Weber, BKV $57,25-180$; tenze, Ablassungsze1t und Echthe1t der Sohrift Eziks "Flderlegung der Irrlehren", "Theolog1sche Quartalschrift" 79/1897/367-398; tenze, D1e Apologie der ohrlstlichen Fahrhe1t bel der Armentern des Altertums, "Der Katho11k" 78/1898/212-231, 311-326; M.Minassian, A propos'd'un pasaage d'Eznik/p. 241/, "Museon" 86/1973/.341-363. 
polemice z Marcjonem ${ }^{6}$.

Byłoby rzecza clekawa przéledzenie tej polemiki u wszystkioh ojców Kó́cloła, wykazanie elementów wspólnyoh oraz wajemnej wapóxzaleznoścl 0jców. Krest11 wspózzaleznośc1 patrologia wspózczesna poświęca coraz więcej uwagl. N1ewatpliwie patryetyczne polemiki z heretykami posiadaja nie tylko analoglezne tresol, ale takze podobny schemat dowodzenta, przejmorany często od woześniejszyoh ojoón. Znajduje to zastosomanie takze polemioe $z$ Marcjonem.

W niniejszym artykule podejmujemy probe ukazania podobienotwa omawianej polemiki u Ireneusza 1 Eznika. Wybór tyoh dwóch autorón nie jest przypadk owy. Wprawdzie Ezn1k zyje około 250 lat pó́niej, lecz jego dzielo wykazuje wyraźna zaleznośd od zyjąoyoh woześntej 0jców greckich, a zwłaszcza od Ireneusza ${ }^{7}$.

Wydaje 818 to zrozumiate, gdyz Jak Informuje Koriun " napisanym przez siebie "Zywocie Mesropan" - Ezn1k do Edessy, w celu zdobyola dz1ez 0jców syryjskich, zatrzymuje sie takze Wonstantynopolu, znajdujgo tu wiele dzlez 0jców greckich. Przywozi je później do Armen11, gdz10 sa tłumaczone na jezyk arménski ${ }^{9}$.

Zależność ojców armenskich, "tym takze Bznika, od Ireneusza znajduje swoje dodatkowe potwierdzenie w fakcle ogromnej popularnoso1 tego 0jca Kośc1oła p literaturze armeńsklej. Wystarozy tu przypomnieb, ze IV 1 V ksiega "Adversus haereses" wersj1 armeńskiej naleza do najstarszych zachowanych przekzadów, a "Epideiks1s..." dotarzo do naszyoh czasón tylko w wersjl armeńsklej, pochodzacej z naj-

6 PO 28,358-432, $\mathrm{BKV}^{2} 57,152-180$.

70 Ezniku z Kolb por.: L.Adontz, "Revue de l'Orient chretien" 25 /1926/309-357; 0.Bardenhewer, Geschiohte der altohr1stichen Literatur, V, Freiburg in Br. 1932, 209-216; V.Inglisian, RAC VII 118-128; P.Ananian, DHGE XVI 293-294; M.Zakrzerska-Dubasowa, Historla Armeni1, Wrookaw 1977, 61-64; K.Stanteok1, EK IV 1484-1485.

6 Das Leben Mesrops, Krit, arm. Aurgabe N.Ak1nian, Wien 1952; przeklad niemieoki: S. Weber, BKV2 57, 185-232.

- Tamze 17, BKV ${ }^{2} 57,220-221$. 
weześniejszego okresu chrześcijańsklej literatury Armen11. W ostatnfch latach Ch. Renoux przekazaz nowe, dotychczas nfeznane, eragnenty armeńskie obu dziez Ireneusza ${ }^{10}$.

Nie jest rzeczz latwa rozstrzygnáb dzisiaj na 1 le Eznik korzystaz bezpośrednio z Ireneusza, a na 1 le z plsm jego "ucznlów", do których zalicza sie powszechnie Metodego z olimpu d Epifantusza z Salaminy. Wladomo, ze Armeńczyk w sko1m dziele posługlwał s18 obszernymi cytataml z traktatu Metodego "0 wolnej wol1"11. W1adomo tez, ze Eplfantusz, który "Haereses" całymi partianl cytuje "Advorous haereses" Ireneusza, był rómnjez znany w najwcześnjejszych przekładach literatury armeńskiej 12 . Hydaje ml s1e jednak, ze porónanie s c h om a $t$ polemik1 z Marcjonem, jak1 stosuje zarówno Ireneusz, jak 1 Eznjk, pozwala wzmocnid teze日 o zaleznośc1 myslowej tego ostatniogo od Biskupa Lyonu ${ }^{13}$.

Swoje dzieło Ireneusz adresuje wprawdzie przeolw wszystkim gnostykom, ale Larcjona 1 marcjonttów wspomina lolennie az 32 razy. Polemika z Marcjonem przewija sie we wsystkich pleotu ksiegach "Adversus haereses", ale mozemy dostrzec w nlej pewne metodyczne uszeregovanie argumentóv.

Najpierw Ireneusz dokonuje krótkiej p $r$ e $z$ e $\mathrm{t}$ a o $\mathrm{j}$ poglądów Marcjona, akcentująo to, co w nich rósni siq od doktryny katolickiej ${ }^{14}$. Nastepnie przechodzi do odparcia nauk1 tegoz gnostyka, opierajizo ste najplerw na argumentach roz u mow yo h. Wskazuje, ze koncepoja dwóch bogów u Marojona jest absuraalna 1 praktycznie prowadzi do atelzmu ${ }^{15}$, podezas gdy wszelkie racje rozumowe

10 Por. Ch.Renoux, Irénée de Lyon. Nouveaux fragments arménies de 1."Adversus haereses" et de l" "Epide1x1s". Introduction, traduction latine et notes, PO 39, Iasc.1, n.178, Turnhout 1978.

11 Zestawiente tekstón por. PO 22, faso.5.

12 Armeńska wersje "Haereses" Eplfaniusza wydał J.Dashian, Wien 1895.

13 metodach polemioznych Ireneusza 1 Eznika zob.: B.Reynders, La polémique de saint Irénéo: Methode et principes, "Rocherohes do Théologle ancienne et médiévale" 7/1935/5-27; C. Williams, Eznik's résumé of Marcionite Doctrine, "Journal of Theologioal Studies" 45/1944/65-73.

$14 I, 27,2 ; I, 28,1, \operatorname{SCh} 264,350,354$.

15 II, 1,$4 ; I I, 3,1$, SCh $294,30,42$. 
musza prowadzić do stwierdzenia, ze 1stnieje jeden Bóg, który jest równocześnte ojcem i stwórca mszystk1ego ${ }^{16}$. Sposob, w jak1 został zrodzony Syn z ojca jest Bozą tajemnioa, której nie tylko nie moze znad Marcjon 1 inni gnostycy, ale takze antołowie 1 arohaniołonie ${ }^{17}$. Swoja polemike Ireneusz rozw1ja dalej w oparciu o argumenty zaczerpntete $z$ T $r$ a d y o $1^{18}$. Wykazuje, jaka jest nauka Apostołón przechowymana w Kośctele. Akcentująo "prioritatem veritatis" zwraca uwage, ze Marojon rozwinal swoja działalność za pontyfikatu Anlceta, który jest juz dziesiatym papiezoin. Przedtem sekta Marcjona nie była znana, nie może więc zamierac pramdy ${ }^{19}$. Hepomina równiez, ze wierny śwladek Tradycj1 - Pollkarp nte zawahaz się nazwac Marcjona "plerworodnym szatana"20.

Następny etap polemiki Ireneusza stanowia argumenty 8 k y pt $u r$ y $\mathrm{s}$ y $\mathrm{c} z \mathrm{n} \theta$. Size swego dowodzenia oplera najpler na Ewangel11 \&w.Jana, który ponad wszelka wątpliwośc stwierdza, ze śmat stał sie przez Chrystusa 1 ze przyszedz on "do swo1chn'1/czemu wyraźnie zaprzeczal 1 marcjonic1/. Wokazuje dalej na wewnętrzne podobleństwo ewangell1 synoptycznyoh ${ }^{22}$, z którymi sto1 w sprzecznośc1 dzlelente przez Marcjona ewangel11 na ozéó, akceptowane 1 odrzucane ${ }^{23}$. Osobno zajmuje sle Ireneusz ewangella św.Lukasza, atakowana przez marcjonitów, podkreślajac, ze szereg faktów z zyola Chryetusa - któro uznaja takze marcjontc1 - znamy waśnle tylko dzięk1 niej ${ }^{24}$. Stąd tez, jeśli darojon odrzuca trzecia erangel1e, pozostaje właściwle bez evangelti 25 .

Dalszy c1zg argumentacje Ireneusza mozna by nazwad argumentaoja d o g m a $t$ y $c$ z a. Ireneusz zauwaza, ze podz1az zastosowany przez Marojona neguje boskość obu bogów. Bóg bowiem z natury

$16 \mathrm{II}, 30,9, \operatorname{SCh} 294,318$.

17 II, 28,6, SCh 294,282 .

$18 \operatorname{III}, 2,1, \operatorname{SCh} 211,26$.

19 III, 4,3, SCh 211,50.

20 III $, 3,4, \operatorname{SCh} 211,40-44$.

21 III, 11,2, SCh 211,144.

22 III, 11, 7, SCh 211, 158.

23 III, 11,9; III, 12,12, SCh 211,170, 230 .

24 III, 14,3, SCh $211,266$.

25 III, 14,4, SCh $211,274$. 
swojej jest dobry. Jeśl1 brakuje mu dobroci, nle jest Bogiem. Bóg zaś, który jest dobry, a który nle jest równocześn1e Sędz1ą, n1e może tez byó uważany za Boga, ponlewaz niemoźliwa jest wtedy sprawiedifośó 1 niemozliwe jest nazwanle Go madrym 0jcem ${ }^{26}$. Prawdę o Bogu moze objawió tylko Jezus Chrystus, bo on jest Synem Bozym, a nte Marcjon 27 .

Ostatni etap polemik1 Ireneusza mozna by nazwać nykazymantem

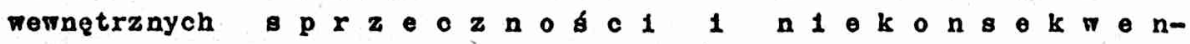
c J 1 w a u e M a c jon a. Biskup z Lyonu zarzuca gnostykowi nleznajomośc P1sma św. ${ }^{28}$, prorradzaca do mylnej interpretacj1 słów Chrystusa w sensie obalan1a Starego Prawa/np. At 5,27; $5,33 / 29$. Ireneusz pollsreśla, ze słów tych nie mozna myrywá z kontekstu, który wskazuje myraźnte na to, ze Chrystus nio obala starego Prawa - jak głosil1 marcjonto1 - leoz je uzupernia 1 rozw1ja ${ }^{30}$. Ten etap polemiki kobezy eerla pytar, tak skonstruowanych przez naszego autora, ze wykazują równocześnte sprzecznośc1 twierdzeń marojonit $\sigma^{31}$. Nie waha sie Ireneusz skierowá do nich wreszole bezpobrednlej zachęty: "Dlcemus autem adversus onnes haereticos, et primo quidem adversus eos qui sunt a slarcione et adversus eos qui sunt similes 1llis, ab altero Deo dicentes esse prophetas: Legite diligentius id quod ab Apostolis est Evangelium nobls datum et legite diligentius prophetias, et Inventetis universam actionom et omnem dootrinam et omnem passionem Domini nostri praedictam in 1psisn32.

Trudno zaprzeczyó, ze poprzez tak uszeregowane etapy argumentaoj1, autor nasz właściwle wyozerpuje polemikę. W dalszej częśo1 dzleza sa raczej pewne nawroty oraz uzupeinienta polemiki. Dotyczy to przede wszystk1m kwest11 zmartwychwstania olal, negowanego przez marojonttów. Ireneusz porugza ja głównte $n$ księdze $V$ "Adversus haereses". Przeprowadza przy tej okazjl egzegeze zdanla św.Pawła "cla-

26 III, 25, 3, SCh 211,482 .

27 IV, 6,2,4, SCh 100,440 .

28 IV, 8, 1, SCh 100,464 .

29 IV, 13, 1, SCh $100,524$.

30 Tamze.

31 IV, 33,2, SCh 100,804 .

32 IV, 34,1, sCh 100,846. 
101 krew nie moga posiąść Królestwa Bozegon /1 Kor 15,50/, Które marojonic1 umazall za podstawe do negaojl zmartwychwstania ciak. Ireneusz wykazuje oparolu o Inne teksty, to Apostoz z oaka pewnofola nauczal z przekonaniem o zmartwyohmstaniu o1ax ${ }^{33}$.

Niemalie na ostatnich kartach swego dzieza doxacza stwierdzenie ad personas mówlac, te marcjoniol 1 inni gnostycy sa "instrumentami szatanan. Przez nich bowlem objawia le szatan, aby zzorzeozyó Bo$\mathrm{gu}^{34}$.

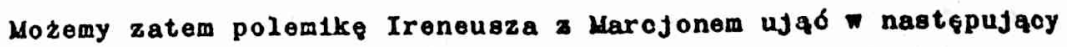
sohemat:

\section{1. przedstawlenie bzędow}

2. argumenty rozumone

3. argumenty $z$ Tradycj1

4. argumenty skrypturystyczne

5. argumenty dogmatyczno

6. wykaz sprzecznośc1 i nlekonsekwenoj1 nauce Marcjona

7. uzupeznienia:

a/ kwestia zmartwychwstania olaz

b/ deprecjacja personalna marojonttón

Spróbujmy teraz spojrzec, Jak skonstruowal polemike a Marcjonem drugi z omawianych 0jcóm Kośloła - Eznik z Kolb. Rozpoozyna podobnie jak Ironeusz - od p r e z e t a j 1 s y t m

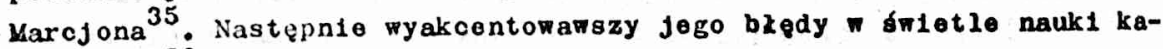
tol10k1ej ${ }^{36}$, przechodzi do $1 \mathrm{ch}$ odparcia, saczynajao od argumentó r o z u m o w y $\circ \mathrm{h}^{37}$. Zauwaza, to koncepoja Marojona o dwob bogach jest nie do przyjecia, ponlewaz od razu sugeruje, ze ponad Bogiem Prawa jest ktoś wyzszy, któremu ten musiazby podlegac ${ }^{38}$.

Jest tu zbieznośó z argumentaoja Ireneusza, który wrecoz zaumaza, ze taka koncepcja Marojona prowadzi do nieskonozonej 110601 ́́⿴囗十) 1 niezliczonej 1 lośc1 bóstw ${ }^{39}$.

35 Ezn1k, De Deo, PO 28,358 .

36 Tamze 359-363.

37 Tamze 364-374.

38 Tamze 364 .

39 Por. Adversus haereses II, 1,4, SCh 294,32. 
z kole1, po przeprowadzentu egzegezy zdanta éw.Pawła o trzec1m nieble $/ 2$ Kor $12,2-4 / 40$, która słuzy mu raczej na poparcie argument 6 rozumowych, Bznik przechodz1 do argumentacjd $s$ k y $p$ t $u$ r y $\mathrm{t}$ y $c \mathrm{z}$ e $\mathrm{j}^{41}$. Zwalcza doketyzm Marcjona, wykazujac odpowiedniml cytatami, ze juz $w$ Starym Testamencie zapowiedziana jest nolelesnośc" Jezusa 42 .

Takze Eznik - podobnie jak Ireneusz 43 porołuje sie na ten sam eragment Ewangel11 św.Jana/1,11/ podkreślając, ze Jezus przyszedł do swojoh, a więc on rspólnie z ojcem jest Panem śriata ${ }^{4}$. Do argumentaoj1 skrypturystycznej armeński 0jciec Koślola dołacza takzo -gzegeze Pawłowego tekstu $/ 1$ Kor $15,24-25 / 45$. Z kole1 Armeńczyk

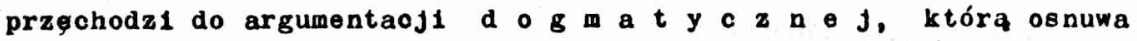
wokół naukı o wybawienı́ dusz z otohłan1. Autor nasz podkreśla, zo moc odkupieńcza Chrystusa obejmuje zarówno te dusze, które tain oozekiwały Jego przyjśla, jak 1 przyszło pokolenta ludzk10. Inaczej bowiem - gdyby konsekwentnie zastosować załozenia marcjonitów - Syn Bözy muslazby być zesłany doplero przy końcu śwlata ${ }^{46}$. W ten sposób Eznik podsuwa wniosek, ze nie mozna stawiá w opozycji dobroci 1 spraw1edliwośol Boga. Spotykamy to takze u Ireneusza w analogicznej częścl polemiki z Marojonem 47 .

2 kole1 armeński 0jcioc Kościoła wskazuje na n 1 e k o n -

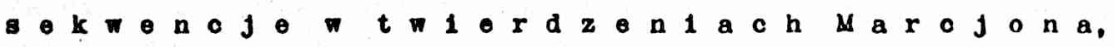
mająo swoje éródło nłeữględnianiu kontekstu całego Plsma św. Eznik analizuje te same cytaty z P1sma 6 w., co Ireneusz /np. Mt 5 , 28; Mt $19,18 / 48$, na które powoływali sie Marcjonicl 1 podkreśla z nao1skiem - podobnie jak Biskup Lyonu - zo Chrystus nie przeolwstawlaz tego co nauczal Staremu Prawu, lecz rozwijaz je, wykazujao pezna zgodnośs mięazy swoim nauczaniem, a tymze Prawem ${ }^{49}$. Dlatego tez poddaje kxytyce asceze marojonitów jako niezgodna z Pismem

40 Bznik, De De0, PO 28, 377-384.

41 Tamze 385.

42 Tamze 389.

43 Por. Adversus haereses III, 11,2, SCh 211, 144.

44 Eznik, De Deo, PO 28,393.

45 Tamze 394-397.

46 Tamze 398-404.

47 Por. Adversus haereses III, 25,3, SCh 211,482.

48 Tamie IV, 12,5; IV, 13,1; SCh $100,520,524$.

49 Ezn1k, De DeO, PO 28,405-406. 
\$พ. 50

Przy samym końcu swojej polemiki Armeńczyk zajmuje sie takze kwestia zmartwychwstania claz ${ }^{51}$. Przeprowadza egzegeze $/ 1$ Kor 15 , 50/, twierdzac - podobnie jak Ireneusz 52 - te sposób niezbity mozna udowodn16, 1z Apostol narodow głosil zmartwychwstanie clał.

Polemika końozy sie nota, dotyczaca osoby Marcjona. Bznik wyraźn1e depreojonuje Marcjona, wykazujac jego nlegodnośs osobista oraz reasumująo równocześnte jego poglagdy 53 .

Niezaleznie wiec od podz1ału, Jaki zastosowall wydawoy omawlanego traktatu "De Deo" polemice Eznika z Marojonem mozna wyrózn1 ó następujace częśc1:

1. przedstawiente błędów

2. argumenty rozumowe

3. argumenty skrypturystyozne

4. argumenty dogmatyczne

5. wykaz nlekonsekwenoj 1 nauce Marojona

6. uzupeznien1a:

a/ kwestia zmartwyohwstania olaz

b/ deprecjacja personalna Marojona.

N1etrudno zaurazyć, ze podział ton odporiada niemal dokładnie podziałow1,jak1 mozemy dostrzec polemice Ireneusza z Marojonem. U Eznika brakuje tylko grupy argumentow z Tradyoj1. Jest to na swój sposób zrozumlałe, jé́l1 weźmie sle pod uwage, ze Eznik pisze swoja polemike $w$ w weku, a w180 muslazby uzupeinió dane Tradyoj 1 o okres dzielący go od Ireneusza. Ireneusz natomiast znająo osobícle uczniów apostolskich sam jest zywym ́́wladkiem Tradycj1.

Zestawlając wi ęo oble polem1k1: Ireneusza 1 Eznika, nalozy wskazać przede wszystkim na podobleństwo zastosowanego ochematu; wyrazajace sle najplerw wanalogleznej kolejnó́c1 atosomanych argumentów 1 1 ch zawartośc1 treściowej, jak 1 podobieństwo metody/takzo w egzegezie Plsma św./ uzywanej dla skuteczniejezego przekonanta marojonltów. Podobleństwo to z pewnośla mamooniloby jeszoze bardziej zestawienie tekstów obu 0job́ Kośloza wanalogicznyoh ozęolach

50 Tamze 407-419.

B1 Tamze 420-431.

52 Por. Adversus haereses V, 13,2-5, 153, 166-182.

E3 Eznik, De Deo, PO 28,432. 
polemikd 1 analiza fllologiczna uzytych pojeć. Wykracza to jednak poza ramy niniejszego artykuzu. Ograniczmy s1e wieg przynajmniej do jednego tylko przykładu. Ireneusz móniąc o zmartwychmstantu clał, podkreśla, ze św.Pawel głosi tę prawdę "clare et manifosto" -

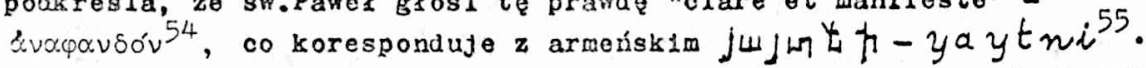

Eznik przy omawianiu tej samej kwestil stwierdza, ze św. Pawez

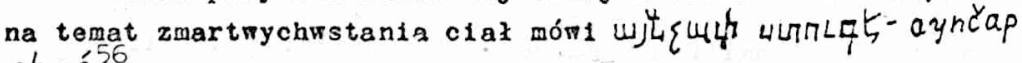
stuge 56 .

Zwroty uzyte przez naszych autorów w tym samym punkc1o polomik1 z Marcjonem 1 przy omawianiu tej samej kwesti1 - sa synonimami.

Porónnanie schematów polemiki pozwala wzmocnid teze, ze Eznik z Kolb nie tylkn znat dzieło Ireneusza, ale takze z niego korzystak, a swojej polemice z Narcjonem był od Ironeusza zalezny, przynajmíej pośrednio. Zaleznośc ta nle pyklucza oryginalnośc1 dzieła Eznika. Godny podkreślenia jest fakt śc1siego zwiłzku patrystycznej literatury armeńskiej z grecką, jak równiez popularność 1 autorytet, jakim cleszył sie w Kośc1ele starozytnym jeszcze w V w., w dalekiej Armentl, śwįty bisisup Lyonu - Ireneusz.

$$
\text { Ks. Bogdan Cz̨̧sz - Poznań }
$$

THE POLEMICS OF IRENAEUS AND EZNIK OF KOLB AGAINST MARCION /Summary/

In the present raport I would like to draw attention to two Fathers of the Church - Irenaeus and Eznk of Kolb - whose works contain polemies against Marcion. Though Eznik lived about 250 years later, his work shows rellance on predecessing Greek Fathers 1ncluding Ironaeus. I find grounds for this in comparison of ways and methods, which Irenaeus and Ezik use in poleinios against Marcion.

It seems therefore, that Irenaeus constructed his polemics against Marcion in the following way: 1. Presentation of errors,

54 Adversus haereses V,13,5, SCh 153,180-182.

55 Por. B. Reynders, Lexique comparé du texte grec et des versions latine, arménienne ot syriaque de 1 "Adversus haereses" de salnt Irénée, Louva1́n 1954.

56 De Deo, P0 28,425. Tłumaczenie Mariesa Merciera brzm1: "Car l'Apôtreà ce point, don $\mathrm{n}$ e o u r o e r t a 1 a la resurrection du corps...". 
2. National arguments, 3. Arguments from the Tradition, 4. Scriptural arguments, 5. Dogmatio arguments, 6. A list of contradiotions and Inconsistenoies in Marolon's teachings, 7 . Supplement: $a /$ the problem of the Resurrection of the body, b/ depreciation of the person of the Marcionltes. Eznik's division corresponds almost 1dentically with the division of Irenaeus's polemics against Marcion. Ezn1k's polemics lacks only the group of arguments from the Tradition. This is undorstandable, if we take into consideration that Eznik wrote his polemics in the fifth oentury so ho would have to complete the data on Tradition for the period dividing him from Irenaeus. Wheress Irenaeus himself was a living witness to the Tradition and knew personally the pupils of the Apostles.

A comparison like this suggests that Enik of Kolb not only knew Irenaeus's work, but also used it and relied on it in his polemics agalnst Marcion. It is difflcult to determine the degree of this reliance. Anyway, it is worth drawing attention to the olose union between patristio Armenien and Groek Literature as well as the popularity of St. Irenaeus in the Ancient Church, proof of which we can find while analysing the work of Eznik of Kolb. 